\title{
Representación de la discapacidad en la prensa digital española
}

\author{
Disability representation in the Spanish digital press
}

\begin{abstract}
Resumen
El propósito de la presente investigación es analizar cuál es el estado actual de la representación de las personas con discapacidad en la prensa digital española. Se ha hecho uso de una triangulación metodológica que ha combinado análisis documental, entrevistas con fuentes expertas y el análisis de contenido de doscientas noticias sobre discapacidad del 2019. Estas fuentes de información han sido analizadas en base a una tabla de indicadores en la que se ha tenido en cuenta diferentes parámetros como son el medio emisor de la información, el género periodístico, la sección en la que se hallan, la fuente informativa, el tipo de discapacidad que se trata en la noticia y cuáles son las tipología de la discapacidad más representadas, el número y sexo de los protagonistas y el enfoque. Los resultados han mostrado que el $70 \%$ de los medios analizados cumplían con las pautas descritas por la Guía de estilo sobre discapacidad para profesionales de los medios de comunicación del Real Patronato sobre Discapacidad.
\end{abstract}

\section{Palabras clave}

Discapacidad, representación, prensa, España, periódicos, noticias, discriminación, medios.

\begin{abstract}
The purpose of the present research is to analyze which is the current state of disabled people representation in the Spanish digital press. It has been used a methodological triangulation that has combined documental analysis, the interview with expert sources and content analysis of two hundred news about disability in 2019. This information has been analyzed on the basis of an indicator chart that has taken into account parameters such as the medium in which the information is broadcast, the journalistic genre, the section in which it is found, the source of information, the type of disability treated in the news and which are the most represented disabilities, the number and biological sex of the protagonists and the approach. The results have shown that $70 \%$ of the analysed media abided by the guidelines described in the publication Guía de estilo sobre discapacidad para profesionales de la comunicación by Spanish Real Patronato sobre Discapacidad.
\end{abstract}

\section{Keywords}

Disability, representation, press, Spain, newspapers, news, discrimination, media.

\section{Gema López-Sánchez <glopez@cesya.es>}

Centro Español del Subtitulado y la Audiodescripción (CESyA). España

\section{Francisco Utray Delgado $<$ futray@hum.uc3m.es>}

Centro Español del Subtitulado y la Audiodescripción (CESyA). España

\section{Belén Ruiz Mezcua \\ <bruiz@inf.uc3m.es>}

Universidad Carlos III de Madrid. España

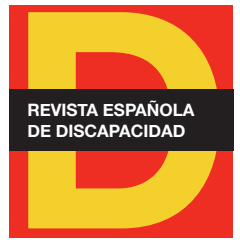

Para citar:

López-Sánchez, G. et al. (2020). "Representación de la discapacidad en la prensa digital española". Revista Española de Discapacidad, 8(2), pp. 33-55.

Doi: <https://doi.org/10.5569/23405104.08.02.02>

Fecha de recepción: 24-01-2020 Fecha de aceptación: 02-11-2020 


\section{Introducción}

De acuerdo con el Informe Olivenza 2017, sobre la situación general de la discapacidad en España (Huete y Jiménez, 2017), cerca de 1.774.800 personas en España - el 5,9\% de la población nacional - tienen algún tipo de discapacidad. Este colectivo es susceptible de formar parte del conjunto de audiencias de los medios de comunicación, así como de convertirse en protagonista de las informaciones que estos compartan.

Los medios de comunicación tienen una vocación de divulgación y servicio público, así como el deber de dirigirse y representar a todos los ciudadanos y ciudadanas en igualdad (UNESCO, 1983). Así queda reflejado en los manuales de estilo que se utilizan habitualmente como referencia en las redacciones periodísticas (AIPET, 1994; FELAP, 1979; Quesada, 1995; RTNDA, 2000; RTVE, 1981; La Vanguardia, 1986; Washington Post, 1999). En este sentido, los medios de comunicación y el resto de tecnologías de la información y las comunicaciones (TIC) se constituyen como un pilar básico de la sociedad de la información, configurando la realidad social e influyendo en las relaciones interpersonales de la población.

"Los medios de comunicación, de manera global, actúan generalmente como elemento uniformador de la opinión de la población, influyendo en las pautas de conducta colectivas" (Ríos y Martínez 1997: 98). Tal es el poder de los medios en la ordenación simbólica del mundo, que su impacto ha sido tenido en cuenta a la hora de realizar investigaciones de índole social, como los estudios sobre la representación del género o la sexualidad, o los análisis sobre la influencia mediática en la opinión pública a la hora de establecer perfiles sobre determinadas minorías.

"La llegada del siglo XXI y la irrupción de la sociedad del conocimiento han conllevado cambios sustanciales en las formas de difusión masiva de la información y en la inteligibilidad de la realidad. El impacto de las tecnologías de la comunicación y los medios audiovisuales, así como la digitalización de la cotidianeidad, no pueden ser negados, interviniendo en la producción de biocódigos que representan la cultura, las identidades o las relaciones sociales" (Aguaded, 2014: 12).

El presente estudio analiza el estado actual en el que se encuentra la representación mediática de la discapacidad, con el objetivo de determinar si los medios de comunicación analizados difunden una imagen estereotipada o discriminatoria de este colectivo, que pueda afectar a sus relaciones con otros miembros de la sociedad.

En concreto, se ha puesto el foco en la prensa digital española. El estudio Accesibilidad de los Principales Medios Digitales de Comunicación, publicado por el Observatorio de Accesibilidad TIC (OATIC, 2016: 111) indica que "la prensa es el medio de comunicación más consumido por Internet por parte de las personas con discapacidad". A través de una encuesta realizada a 412 personas con diversas discapacidades se mostró que el $78,7 \%$ de los encuestados había accedido a la prensa por Internet en el mes del estudio

La Organización Mundial de la Salud (OMS), define la discapacidad como "un fenómeno complejo que refleja una relación estrecha y al límite entre las características del ser humano y las características del entorno en donde vive"1. Esta definición muestra la discapacidad no solo como una condición de salud propia de la persona, sino como el resultado de la interacción entre las limitaciones humanas y el contexto social en el que se desenvuelven.

1. Definición sobre discapacidad en el apartado de Temas de Salud de la página web en español de la Organización Mundial de la Salud (OMS). Disponible en https://www.who.int/topics/disabilities/es/. 
Si el contexto social viene predeterminado por los diferentes tipos de relaciones humanas, y dichas relaciones pueden verse afectadas por la capacidad persuasiva de los medios de comunicación, es posible deducir que los medios de comunicación tienen el poder de potenciar o disminuir la discapacidad de una persona, afectando, por ende, a su calidad de vida.

Teniendo estas consideraciones en cuenta, el estudio analiza de qué modo la prensa digital representa a este colectivo, y si el tratamiento que recibe se puede considerar normalizado con respecto al utilizado para informar de los hechos que involucran a personas sin discapacidad.

Los resultados de esta investigación también pueden servir como referencia para los profesionales de la comunicación mediática, así como a instituciones y asociaciones, en la redacción de futuras guías de estilo y de buenas prácticas para el tratamiento de la discapacidad en la elaboración de contenidos informativos.

"Concebimos sociedades de la información y la comunicación que sean incluyentes, fundadas en la dignidad humana, los derechos humanos y el diálogo intercultural para el avance de la paz mundial, en un ambiente libre de la violencia y el odio... Sociedades donde cada ciudadano/a tenga la oportunidad no solo de acceder a la información, sino también de producirla y ejercer su creatividad. Sociedades que movilicen la solidaridad global para superar las inequidades sociales y geográficas y contribuyan a una distribución más equitativa de los recursos tecnológicos e informativos" (Burch, 2003: 170).

Los objetivos de la investigación son:

- O1. Observar si se están cumpliendo los códigos deontológicos y los manuales de estilo.

- O2. Analizar si la representación que se da de este colectivo es formalmente equitativa con respecto al conjunto de españoles y españolas que no presentan discapacidades.

- O3. Analizar la representación de las diferentes discapacidades y estudiar qué tipo de cobertura mediática se hace de cada una.

- O4. Establecer un perfil sobre los protagonistas de las noticias con discapacidad.

- O5. Comprobar en qué secciones y géneros periodísticos es posible encontrar estas informaciones.

En definitiva, esta investigación establece un perfil que relaciona a la prensa española con la representación del colectivo de personas con discapacidad.

La hipótesis de partida es que las noticias publicadas en prensa digital que incluyen a personas con discapacidad no siguen las normas de las guías de estilo y, por tanto, ven comprometida su misión de paliar la discriminación. El director del Real Patronato sobre Discapacidad, Jesús Ángel Celada López, afirmó durante el turno de preguntas de la conferencia 'Las políticas de la discapacidad en España' del 20 de febrero de 2019 en la Universidad Carlos III de Madrid que la imagen que los medios de comunicación aportan sobre la discapacidad es "un tema fundamental y clave (...) que preocupa al colectivo de personas con discapacidad" y declaró que "en la última jornada de este tema se trató cómo se abordaba la discapacidad en las redes sociales y los mensajes solían ser negativos, con penas, con tristeza... Había pocos de éxito". Por tanto, para verificar esta hipótesis, se ha analizado el grado de cumplimiento de las normas de estilo en una muestra de doscientas noticias publicadas en periódicos digitales. 
Tras una observación preliminar a nivel de persona usuaria/lectora de medios, se ha establecido la segunda hipótesis, más centrada en el estatus de la noticia - conferido según su categorización en las secciones del periódico- que establece que la sección en la que predomina esta información es la correspondiente a sociedad. El director general de Servimedia, José Manuel González, en la entrevista de investigación realizada para el presente artículo científico -y que se desglosará más adelante en el apartado de metodología-, expuso que "tradicionalmente, la discapacidad ha venido englobada bajo el lema social. En discapacidad se habla de personas y automáticamente en todas las redacciones ha ido a parar a sociedad". Por otro lado, la redactora de la Agencia EFE Ana Rodrigo ha confirmado que estas noticias se suelen englobar en la sección de sociedad porque "en la sección de sociedad se habla de colectivos, vecinos, mayores, mujeres...".

La tercera hipótesis plantea que los medios nacionales publican más noticias sobre discapacidad que los locales y regionales. En tanto que se presupone que estos medios, dirigidos a públicos más generales y que cuentan con una mayor popularidad y cifras de audiencias, han de contar con una representación mayor de todos los colectivos, incluyendo colectivos más minoritarios como lo son las personas con discapacidad.

\section{Marco teórico}

Uno de los pilares fundamentales sobre los que se basa el marco teórico de la presente investigación son los estudios sobre la influencia de los medios de comunicación masivos y los estudios de la representación, con un especial interés en cómo la creación de una determinada representación sobre un colectivo minoritario puede dar lugar a conductas discriminatorias hacia ese colectivo por parte del público.

Estas ramas de investigación tienen sus orígenes en la denominada Escuela de Birmingham, nacida en 1964 con la creación del Center of Contemporary Cultural Studies (CCCS), que fomentó la proliferación de un conjunto de estudios desarrollados desde diferentes perspectivas que ponían de manifiesto la necesidad de "abordar el estudio de la cultura propia como un terreno de análisis conceptualmente importante, pertinente y teóricamente fundado" (Quirós, 2003: 1). Para ello, uno de los focos de atención fue la investigación sobre la influencia de los medios de comunicación de masas (mass media studies) en la opinión pública y en la conformación del imaginario colectivo y la cultura de la sociedad de posguerra.

Los estudios sobre la representación han sido abordados, entre otros autores, por Stuart Hall, que sustituyó a Richard Howard en la dirección del CCCS. Este autor, interesado en los procesos de recepción y descodificación de los mensajes mediáticos por parte de las audiencias, definió la representación como "una parte esencial del proceso por el cual el significado es producido e intercambiado entre miembros de una cultura" (Hall, 1997:15). El significado nos proporciona un sentido de nuestra propia identidad, de quiénes somos y a qué pertenecemos (Spivak, citada en Rodríguez, 2006: 40); por lo tanto "está relacionado con las cuestiones de cómo es usada la cultura para demarcar y mantener la identidad dentro de un grupo y con relación a otros" (Hall, 1997: 3).

Estas definiciones concuerdan con el efecto excluyente que podría tener una determinada información sobre el colectivo de personas con discapacidad ('los otros') en relación a aquellas sin discapacidad ('noso- 
tros'). De hecho, la importancia del lenguaje como objeto de configuración de la realidad (Balas, 2006: 318; García, 2006: 1) es un elemento clave para el estudio de la representación de los colectivos, como sucede en el caso de los recientes estudios sociales feministas sobre la cosificación de la mujer y su papel pasivo/ activo en el contexto histórico (Fernández, 2004; Garro, 2011). En la Guía de estilo sobre discapacidad para profesionales de los medios de comunicación (Hernández y Peñas, 2019), se especifica la necesidad de desterrar del uso periodístico "vocablos impropios o vejatorios tales como discapacitado, minusválido, retrasado, oligofrénico, incapacitado, inválido, tullido, lisiado, imposibilitado, impedido, subnormal, loco o trastornado" (Hernández y Peñas, 2019: 58).

Gayatri Spivak, en su libro ¿Pueden hablar los subalternos? (citado en Rodríguez, 2006), hace otra referencia al concepto de representación -en este caso, orientado al postcolonialismo- definiéndolo como "el retrato que de un sujeto se hace y con el significado que su existencia adquiere". Además, también comprende la representación desde una segunda perspectiva en la que se entiende como "el papel ejercido por una persona que asume los intereses de otros y habla en nombre de ellos ante el Estado". Esta última definición encaja con la labor que ejercen los medios de comunicación, entre ellos, la prensa digital.

En resumen, podemos establecer que una mala representación de las personas con discapacidad, por parte de los medios de comunicación, puede influir en su exclusión social.

Este estudio también encuentra sus bases en las investigaciones sobre la influencia de los medios de comunicación de masas en los comportamientos sociales, aplicado a la representación social de las minorías. En este sentido, Bernadette Califano (2015: 61-79) indica que "los medios de comunicación son constructores de la actualidad política y participantes de conflictos políticos en un doble sentido: tanto desde la influencia que puedan ejercer a través de las noticias sobre la opinión pública en general y sobre la élite política en particular, como desde las negociaciones extraperiodísticas que los dueños y operadores de los medios puedan mantener con otros actores para influir en el proceso de toma de decisiones políticas".

La teoría de cultivo propone un proceso de identificación de la realidad del mundo con la realidad televisiva. De acuerdo con la obra "Sociología de la comunicación" de Antonio Lucas Marín et al. (2003), los grandes espectadores de televisión - los que pasan más de cuatro horas diarias viéndola- perciben a través de ese medio una realidad que difiere del mundo auténtico tanto en el contenido de los hechos como en los papeles sociales, entre los que se incluye la representación de minorías (Marín et al., 2003: 234), dentro de las cuales podríamos considerar a la discapacidad. Se llega a la conclusión de que estas audiencias tienden a pensar que esta realidad televisiva es similar a la realidad auténtica. En cualquier caso, hay que tener en cuenta que ni todos los mensajes que aporta la televisión - ni otros medios - están homogeneizados, ni todos los individuos tienen un contacto equivalente con la realidad social (Marín et al., 2003: 237).

Aunque esta teoría se ha confeccionado pensando en el medio televisivo, se aplicará el presente modelo a la prensa digital, al considerarse un medio con la suficiente entidad como para crear una imagen propia del mundo. Un ejemplo de esto podría ser la capacidad de viralización de noticias reales y fake news (noticias deliberadamente falsas) presentada por los medios online. Estos aportan como valor añadido una facilidad mayor que los medios tradicionales para compartir contenidos. De este modo, se puede afirmar que "la agenda de la ciudadanía está elaborando nuevos canales de influencia en el ámbito digital" (Magallón, 2018: 274). 
En una línea semejante a la teoría del cultivo, Health y Bryant respaldan la teoría de la socialización, que pone el énfasis en que una elevada exposición a los medios enseña a los receptores los comportamientos que se consideran adecuados, por ejemplo, el aprendizaje de los roles de género o la estereotipificación de determinadas minorías (Marín et al., 2003: 237), incluido el colectivo de personas con discapacidad, o la percepción del fenómeno migratorio desde una perspectiva negativa (García, 2007: 27), entre otros.

Pero si las teorías del cultivo y de la socialización explican cómo los medios influyen en la realidad, se hace imprescindible describir qué es esa 'realidad'. El sociólogo alemán Niklas Luhmann defiende que "en la vida cotidiana se presupone que el mundo es como es, y que la diversidad de opiniones es resultado de perspectivas, experiencias y recuerdos subjetivos" (Luhmann, 2000: 111), haciendo hincapié en que las ciencias sociales solo admiten un relativismo histórico, étnico o cultural. En consonancia con las teorías de Health y Bryant, Luhmann expone que los medios tratan de configurarse como una 'inteligencia moral' que represente los valores de una determinada sociedad y establezca quiénes son los buenos y quiénes son los malos (Luhmann, 2000: 114).

Además de los estudios culturales y los estudios de representación y la identificación, es importante tener en cuenta estudios sobre la propia discapacidad. Aunque la mayoría se refieren a cuestiones de índole médica y/o terapéutica, también existen ciertos estudios sobre la imagen asociada a las personas con discapacidad. Loles Díaz Aledo publicó en 2007 el estudio La representación de la discapacidad en los medios de comunicación. Cómo lograr una presencia más adecuada, tras haber analizado durante quince días un periódico regional por cada comunidad autónoma, a excepción de Madrid, y diez emisoras regionales que consideró representativas. Las conclusiones de dicha investigación estaban más orientadas a los intereses informativos de las personas con discapacidad y a la elaboración de una serie de normas para el tratamiento informativo de la misma (Díaz, 2007).

Por otra parte, ya en 1986, Pablo del Río realizó un análisis de los contenidos de la información sobre las personas con discapacidad en la prensa general y comparó los resultados con los obtenidos en otros medios de comunicación. Entre sus conclusiones, destaca la existencia de tonos 'paternalistas', contenidos destinados a generar lástima en el espectador y posturas marginadoras (Del Río, 1986: 90), poniendo el énfasis en los aspectos negativos o limitativos de las discapacidades (Del Río, 1986: 94).

También se ha tenido en cuenta el estudio Percepción de la imagen de las personas con discapacidad por los profesionales de los medios de comunicación publicado por la Fundación ONCE) y dirigido por Mariano Cebrián (2010), que llega a la conclusión de que la presencia de las personas con discapacidad en los medios de comunicación "no se corresponde con la realidad social, y esta discriminación constituye un obstáculo muy importante, ya que una mayor presencia en los medios contribuye a que se consolide la integración" (Cebrián, 2010: 4). Además, indica que los ciudadanos con discapacidad, al aparecer en los medios, asumen un papel representativo de su discapacidad (Cebrián, 2010: 5).

Esta idea subyace en la confección de uno de los indicadores del presente estudio, que ha tratado de categorizar las doscientas noticias en aquellas que tuvieran como protagonistas a colectivos y las que fueran protagonizadas por un individuo.

Desde el estudio de las expectativas que tienen las personas con discapacidad sobre los medios audiovisuales (Utray et al., 2010) hasta la investigación sobre la accesibilidad a los mismos (Orero et al., 2009; 
Bariffi et al., 2008), se ha comprobado la importancia que los medios de comunicación tienen para la creación de las identidades y las relaciones interpersonales. En este contexto, investigadores como Juan Antonio Cortés-Fuentes y Beatriz Correyero-Ruiz (2017: 56) opinan que el acceso a los medios tradicionales como la televisión, la radio y la prensa en papel por parte de las personas con discapacidad es muy limitado.

Las nuevas tecnologías de la comunicación han posibilitado el desarrollo de Internet como medio de intercambio informativo, abriendo el camino para el desarrollo de la sociedad digital (Terceiro, 1996). En este contexto sociocultural, la investigadora Marie-Christine Moreau (2005: 584) sugiere que la prensa digital, al ocupar una posición intermedia entre la información, la comunicación y la diversión, conecta mejor con las audiencias.

El ciberperiodismo no ha terminado con la prensa escrita, pero ha tenido un éxito que ha influido en detrimento del resto de medios de comunicación tradicionales. Periódicos como El País, El Mundo, La Razón o ABC se han visto obligados a ofrecer informaciones en formato digital para poder competir con medios genuinamente digitales como eldiario.es. Todos ellos han sido analizados en la presente investigación.

\section{Método}

La investigación se ha basado en una triangulación metodológica que ha incluido análisis bibliográfico, análisis cuantitativo de doscientas noticias de prensa digital y entrevistas con fuentes expertas.

Las entrevistas previas han servido para encauzar la investigación y las posteriores para canalizar y contrastar las conclusiones del estudio y su discusión. En cuanto a la muestra elegida -los participantes seleccionados para ser entrevistados-, la primera aportación utilizada en el marco de este estudio ha correspondido Jesús Ángel Celada López, director del Real Patronato sobre Discapacidad durante el turno de preguntas de su conferencia 'Las políticas de la discapacidad en España' del 20 de febrero de 2019 en la Universidad Carlos III de Madrid. De forma previa al análisis cuantitativo, se entrevistó a Belén Ruiz, responsable del Centro Español del Subtitulado y la Audiodescripción (CESyA), en un encuentro que ayudó a asentar nichos de interés del colectivo que fueron de gran utilidad a la hora de establecer los indicadores que se desarrollarán en el siguiente punto. Posteriormente se entrevistó a Ana Rodrigo, redactora de Asuntos Sociales en la Agencia EFE; José María Prieto, director del gabinete de comunicación de la ONCE, y José Manuel González, director general de Servimedia, cuyos comentarios han sido encauzados a la elaboración de las conclusiones y la discusión de esta investigación. La metodología de las entrevistas, por tanto, se ha basado en la realización de entrevistas de tipo semiestructurado y presencial.

Con la revisión documental como referencia y fuente de consulta constante, el grueso del trabajo se ha referido a una investigación cuya herramienta principal ha sido el buscador de Google que, pese a no aportar resultados estadísticamente representativos, presenta la ventaja de lograr una aproximación más cercana al punto de vista de las audiencias que consumen información a través de esta vía. El periodo de tiempo 
abarcado han sido los meses de abril y mayo de 2019. Si bien es cierto que el algoritmo de Google también ha presentado noticias anteriores a dichos meses, se trata de datos aislados.

Google es la página web más popular y el motor de búsqueda más utilizado a nivel mundial. Según los datos de la consultora NetMarket Share correspondientes al año 2017, Google supera con creces la mayoría absoluta en el mercado de navegadores online gracias al 58,64\% que disfruta Chrome, casi tres veces más que el $18,95 \%$ de Internet Explorer o el $11,79 \%$ de Firefox. Esta es la razón por la que se ha utilizado este navegador y no otros. En aras de evitar la influencia del llamado efecto de la "burbuja de filtro" (Pariser, 2011) - por el cual los algoritmos de los sitios web y las cookies proporcionan contenido personalizado a cada usuario-, para este estudio se utilizó un ordenador nuevo al que se le instaló Google Chrome.

El siguiente paso ha consistido en analizar doscientas noticias sobre discapacidad publicadas en la prensa española, posicionadas en el buscador de Google en función de su popularidad (mayor número de búsquedas de los usuarios). El término introducido en la barra de búsqueda ha sido la palabra 'discapacidad'. La búsqueda se ha filtrado seleccionando únicamente los enlaces a medios de prensa digital, incluyendo en el análisis todos los resultados obtenidos por orden de búsqueda. Estas noticias se han seleccionado y categorizado en función de los siguientes criterios, conforme a los cuales se ha creado una tabla de indicadores (Tabla 1).

Estos indicadores han servido para la categorización de las noticias. Los resultados derivados de esta segunda fase de la investigación han sido debatidos y contrastados con personalidades del mundo de la comunicación relacionados con entidades afines al colectivo de personas con discapacidad.

Es necesario tener en cuenta que, para que los resultados de la aplicación del método puedan ser extrapolables, es recomendable que el presente estudio sea realizado de forma periódica - preferiblemente de forma anual- para poder realizar una serie de comparativas pertinentes en el futuro que permitan comparar la evolución de la representación de las personas con discapacidad en la prensa digital nacional con una mayor precisión y exactitud. 


\begin{tabular}{|c|c|}
\hline Medio emisor & $\begin{array}{l}\text { Para averiguar si los periódicos digitales con más noticias sobre discapacidad son también } \\
\text { aquellos con un mayor número de lectores. }\end{array}$ \\
\hline Género periodístico & $\begin{array}{l}\text { Se han categorizado las noticias en géneros informativos (información y reportaje objetivo), } \\
\text { géneros interpretativos (reportaje interpretativo y crónica) y géneros de opinión (artículo o } \\
\text { comentario), conforme a la teoría normativa de los géneros periodísticos acuñada por José } \\
\text { Luis Martínez Albertos en 1989. Esta teoría surge por la extrapolación de la teoría clásica de } \\
\text { los géneros literarios (Martínez-Hernando, 1998: } 51-60 \text { ) derivados de la tradición europea y } \\
\text { anglosajona (Parratt, 2001). }\end{array}$ \\
\hline Sección & Cuantificación de las secciones en las que se publican más noticias sobre discapacidad. \\
\hline Fuente & Para estudiar de dónde proviene la información sobre discapacidad. \\
\hline Tipo de discapacidad & $\begin{array}{l}\text { Se ha acotado la clasificación en discapacidades físicas, sensoriales, intelectuales }{ }^{2} \text {, } \\
\text { psicosociales, enfermedad mental }{ }^{3} \text { o no indicado". }\end{array}$ \\
\hline $\begin{array}{l}\text { Discapacidad } \\
\text { predominante }\end{array}$ & En aras de conocer cuál es la discapacidad más mediática en prensa digital. \\
\hline $\begin{array}{l}\text { Número de } \\
\text { protagonistas }\end{array}$ & $\begin{array}{l}\text { Se pretende comprobar el número de noticias que tienen un protagonista colectivo o uno } \\
\text { individual, que puede o no ser utilizado como personaje representante de su discapacidad } \\
\text { (Cebrián-Herreros, 2010: 5). }\end{array}$ \\
\hline $\begin{array}{l}\text { Sexo de los } \\
\text { protagonistas }\end{array}$ & Masculino o femenino. \\
\hline Enfoque & $\begin{array}{l}\text { Se ha analizado la dualidad entre las noticias con enfoque positivo }{ }^{4} \text { y negativo }{ }^{5} \text {, además de los } \\
\text { teletipos de carácter neutro. La cuarta categoría será el punto de vista reivindicativo, puesto que } \\
\text { muchas de las noticias sobre personas con discapacidad en los medios de comunicación versan } \\
\text { sobre la reivindicación de derechos y la denuncia social (Fernández, 2017: 19). }\end{array}$ \\
\hline $\begin{array}{l}\text { Nivel de cumplimiento } \\
\text { de la Guía de estilo } \\
\text { sobre discapacidad } \\
\text { para profesionales de la } \\
\text { comunicación (Hernández } \\
\text { y Peñas, 2019) }\end{array}$ & $\begin{array}{l}\text { Se ha elegido utilizar este manual como un referente por ser el más reciente en su materia de } \\
\text { los publicados en España y por la credibilidad que le otorga haber sido publicado por el Real } \\
\text { Patronato sobre Discapacidad y aceptado por entidades privadas íntimamente relacionadas con } \\
\text { este colectivo, como Servimedia u ONCE. Concretamente, se han atendido a las instrucciones } \\
\text { aportadas en el apartado "El lenguaje correcto para cada tipo de discapacidad" (Hernández y } \\
\text { Peñas, 2019: 49-77). }\end{array}$ \\
\hline
\end{tabular}

Fuente: elaboración propia.

2. El Real Decreto 1972/1999, de 23 de diciembre, de procedimiento para el reconocimiento, declaración y calificación del grado de minusvalía. Dicho texto legislativo divide los tipos de discapacidades en tres grupos: discapacidades físicas, intelectuales y sensoriales (visual y auditiva).

3. Desde 2008, la Convención sobre los Derechos de las Personas con Discapacidad de la Organización de las Naciones Unidas reconoció a las personas con discapacidad mental o psicosocial.

4. Entendiendo el término 'positivo' desde su quinta definición por el Diccionario de la Real Academia Española: "Optimista, inclinada a ver el aspecto favorable de las cosas".

5. Entendiendo el término 'negativo' desde su quinta definición por el Diccionario de la Real Academia Española: "Pesimista, inclinada a ver el aspecto desfavorable de las cosas". 


\section{Discusión de resultados}

Los resultados no son estadísticamente concluyentes, pero sí son representativos en cuanto a que permiten elaborar una aproximación al tipo de información obtenida por las personas receptoras/lectoras que busquen datos en la prensa digital.

En primer lugar, se ha refutado la hipótesis de partida de que las noticias publicadas en prensa que incluyen a personas con discapacidad no cumplen las normas de la Guía de estilo sobre discapacidad para profesionales de los medios de comunicación (Hernández y Peñas, 2019). Se ha comprobado que la mayoría de las informaciones digitales analizadas, el 70 \%, cumplen con las indicaciones de dicha guía. Asimismo, todos los entrevistados coinciden en que la situación de la discapacidad en los medios de comunicación está mejorando paulatinamente, aunque todavía no se puede hablar de una completa normalización.

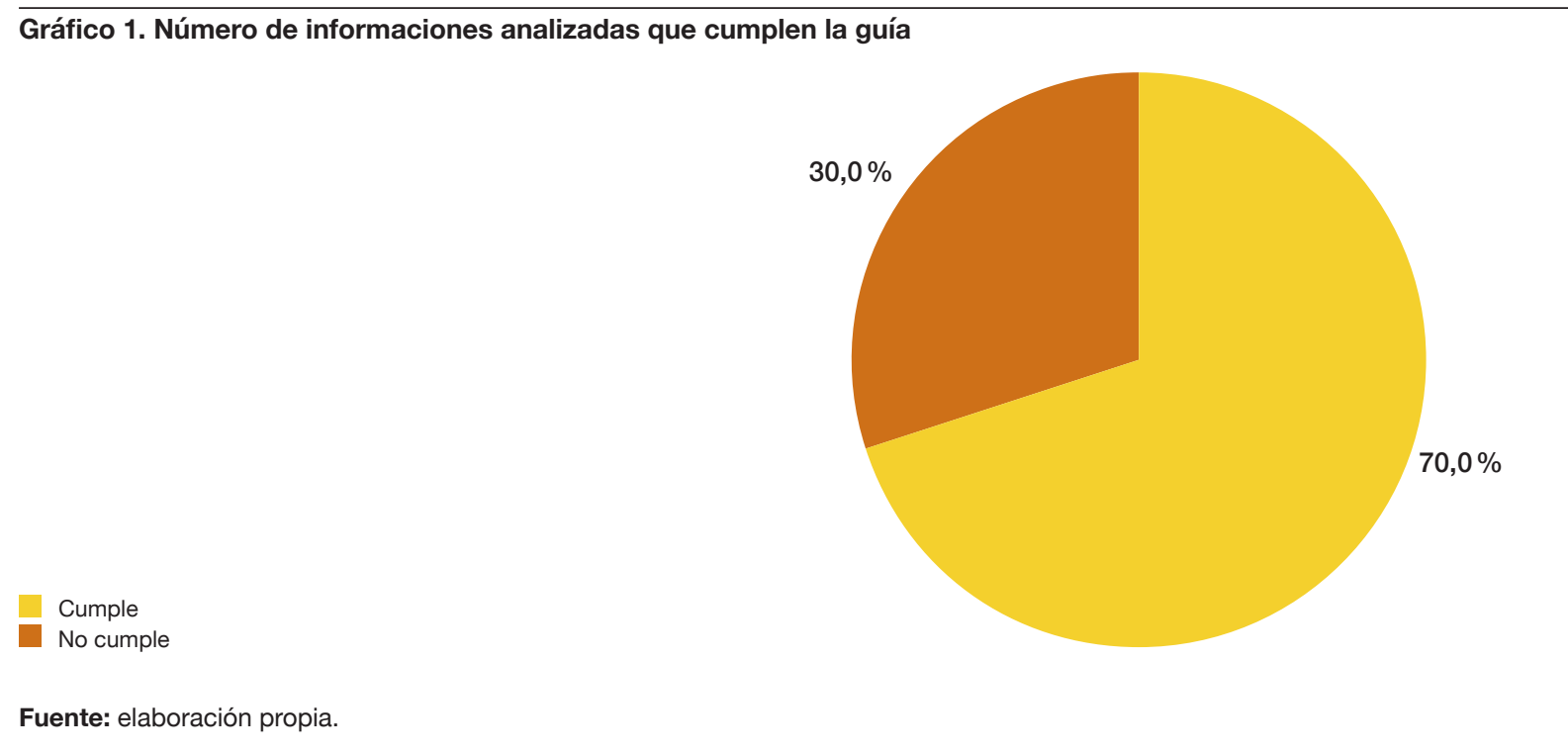

Dentro del $30 \%$ de las noticias analizadas que no cumplen la guía, hay medios que deben su falta a un uso del lenguaje que la guía considera inapropiado, por ejemplo, utilizando el término "minusválido" en lugar del de "persona con discapacidad"; o dotando de carga negativa a la discapacidad mediante la utilización de verbos como "padece una discapacidad" en lugar de "tiene una discapacidad" (Hernández y Peñas, 2019: 56). Ana Rodrigo indica que "EFE es muy cuidadosa con el lenguaje en general e inclusivo, en particular", y que en la redacción de noticias e informaciones siempre se tiene en cuenta "hacerlo con el respeto máximo hacia las personas y colectivos a los que nos referimos". En este caso, los entrevistados han coincidido en distintos niveles con la necesidad del uso del lenguaje inclusivo.

También se cometen faltas relacionadas con la utilización de estereotipos - la persona con discapacidad con una imagen heroica (Hernández y Peñas, 2019: 13) o, su contrario, la persona con discapacidad como 
representación del sufrimiento - o la búsqueda del sensacionalismo a través de representaciones dramáticas (Hernández y Peñas, 2019: 62). El análisis ha contado con un indicador para medir el tono de las noticias y comprobar si realmente este tratamiento negativo tiene un uso generalizado. En contra de esta postura, los resultados han mostrado que la mayoría de las informaciones sobre discapacidad analizadas tenían un carácter positivo, si bien el número de noticias negativas, reivindicativas y neutras está bastante equilibrado.

\section{Gráfico 2. Tono de las informaciones analizadas}

$\begin{array}{r}80 \\ \hline 70 \\ \hline 60 \\ \hline 50 \\ \hline 40 \\ \hline 30 \\ \hline 20 \\ \hline 10 \\ \hline 0 \\ \hline\end{array}$

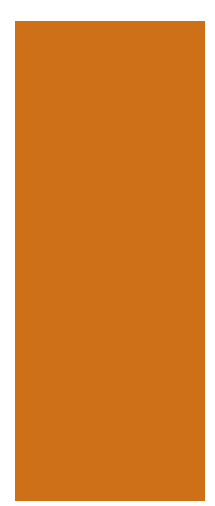

Positivo

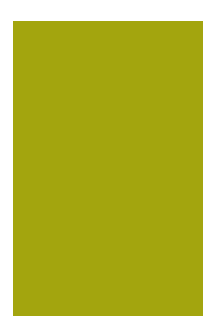

Negativo

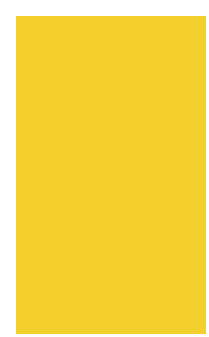

Reivindicativo

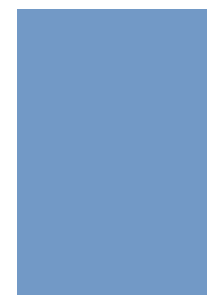

Neutro

Fuente: elaboración propia.

Dentro del $30 \%$ de noticias que no cumplen la guía, también se han encontrado ciertos casos que podrían entrar en conflicto con la necesidad de "evaluar si la mención explícita a la discapacidad es o no relevante para la enjundia de la información, en especial en el titular" (Hernández y Peñas, 2019: 59). Los expertos consultados al respecto en las entrevistas han coincidido en el peligro que tiene poner en el titular que el autor de unos hechos delictivos tenga discapacidad, puesto que se puede producir una asociación entre discapacidad y conductas delictivas que provoque una generalización en detrimento de la imagen pública del colectivo con discapacidad. Sin embargo, no resulta tan sencillo señalar si en la noticia en la que la víctima es la que tiene discapacidad es conveniente o no aportar dicho dato en el titular, aunque coinciden en que es relevante en el cuerpo de la noticia.

Además, un mismo medio tiene noticias que cumplen la guía y otras que no. José Manuel González (Servimedia) y José María Prieto (ONCE) están de acuerdo en que se debe a que cada noticia depende de un periodista y los estilos literarios de la plantilla de trabajadores de la redacción no siempre están unificados por las guías y manuales de estilo. Señalan que los flujos de información de las redacciones son difíciles de controlar incluso por la figura del redactor jefe, debido a la enorme cantidad de noticias y al poco tiempo del que se dispone.

Por otro lado, en cuanto al análisis de las fuentes principales de las informaciones, el $38 \%$ provenían de notas de prensa y actos organizados por entidades directamente relacionadas con la discapacidad. Dentro 
de estas instituciones, la que ha contado con más contenidos relacionados ha sido el CERMI (21 noticias), seguido de la ONCE (8 noticias). Estas entidades influyen en que estos medios traten las temáticas que les son afines. José María Prieto (ONCE) reflexiona acerca de una tendencia de los medios a reproducir notas de prensa en lugar de buscar sus propios contenidos más allá de los temas políticos y económicos, pero reconoce que este hecho beneficia a instituciones como la suya, puesto que les permite obtener un mayor impacto mediático con sus noticias.

\begin{tabular}{l}
\hline Tabla 2. Noticias provenientes de entidades relacionadas con la discapacidad \\
\begin{tabular}{|l|c|}
\hline ONCE & 8 noticias \\
\hline CERMI & 21 noticias \\
\hline COCEMFE & 5 noticias \\
\hline Plena Inclusión & 7 noticias \\
\hline Somos diversos & 2 noticias \\
\hline Otros & 33 noticias \\
\hline
\end{tabular}
\end{tabular}

Fuente: elaboración propia.

Las agencias de noticias también son fuente de contenidos sobre discapacidad para prensa local y nacional. La Agencia EFE y Servimedia son citadas como fuente informativa en 30 de las noticias analizadas (15 y 15 cada una). Europa Press en 8 noticias. La mayoría de los periódicos analizados con un mayor número de noticias sobre discapacidad, citan a las agencias como fuentes en algunas de esas informaciones, tal y como se muestra en la tabla 3. Las aportaciones de Servimedia son las que más coinciden con la Guía de estilo. José Manuel González (Servimedia) destaca que esta agencia nació con el objetivo de dar visibilización y normalización al colectivo de personas con discapacidad.

Centrándonos en los propios medios que comparten las informaciones, los diarios analizados que más noticias sobre discapacidad comparten son La Vanguardia, 20 Minutos, El Economista y ABC. Este dato nos aporta información sobre cuáles son los medios que más información relacionada con las personas con discapacidad comparten o que están mejor posicionados en términos de SEO. En cualquier caso, son estos medios y sus noticias las que tienen mayor probabilidad de alcanzar audiencias más amplias y, por tanto, su visión sobre la discapacidad será la que compartan con sus lectores y lectoras.

Por otra parte, el gráfico 4 permite establecer una comparativa entre las noticias sobre discapacidad publicadas por un mismo medio. Podría esperarse que por ser informaciones publicadas y escritas por profesionales de una misma redacción, respondieran a criterios estandarizados y uniformes, sin embargo, se perciben fuertes discrepancias entre noticias que cumplen y que no cumplen con la Guía. De acuerdo con los datos, El Economista es el medio de prensa digital con mayor número de noticias sobre discapacidad que, además, cumplen la Guía de estilo. Es necesario destacar que todas las informaciones analizadas de este diario citan como fuente a Servimedia. 


\section{Gráfico 3. Diarios con mayor número de noticias sobre discapacidad}

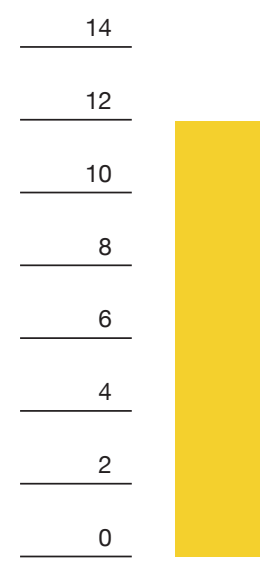

La Vanguardia

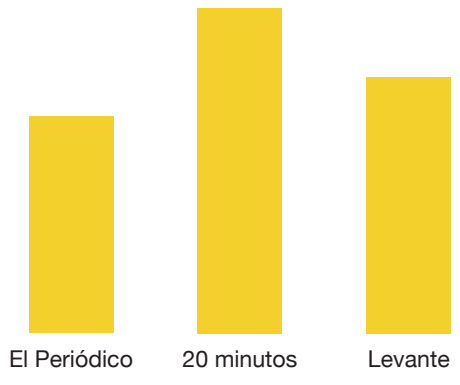

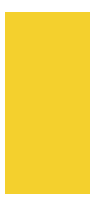

El País

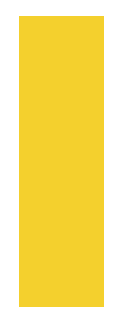

El Economista El Faro de Vigo

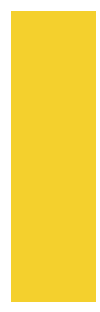

$\mathrm{ABC}$

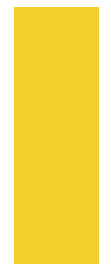

Eldiario.es

Fuente: elaboración propia.

\section{Gráfico 4. Nivel de cumplimiento de la guía de los periódicos con mayor número de noticias sobre discapacidad}

9

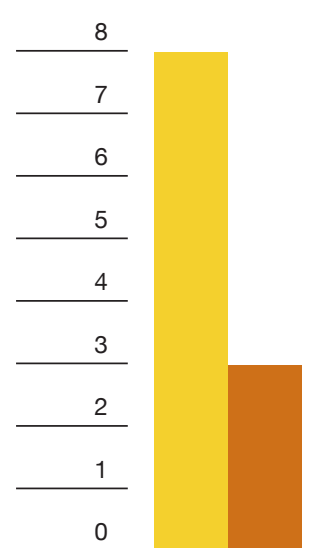

La Vanguardia

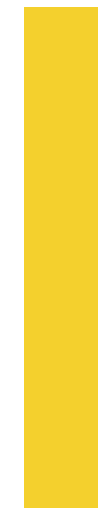

El Economista

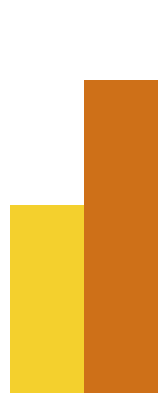

$\mathrm{ABC}$

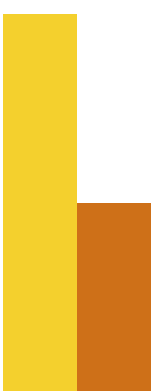

Eldiario.es

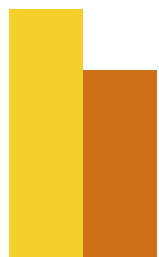

Levante

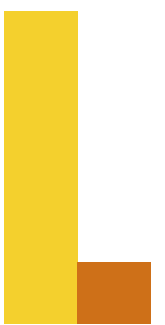

El Faro de Vigo

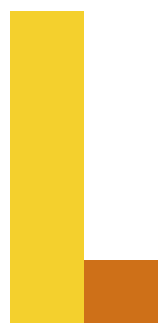

El Periódico

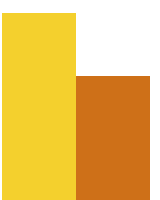

El País

Cumple

No cumple

Fuente: elaboración propia. 
Tabla 3. Periódicos con mayor número de noticias sobre discapacidad en relación al uso de agencias como fuentes

\begin{tabular}{|l|c|c|c|c|l|}
\hline & & Cumplen & No cumplen & Agencia & \\
\hline La Vanguardia & 12 & 8 & 3 & 10 & EFE y Europa Press \\
\hline 20 Minutos & 9 & 5 & 4 & 3 & Europa Press \\
\hline El Economista & 8 & 8 & 0 & 8 & Servimedia \\
\hline ABC & 8 & 3 & 5 & 2 & EFE \\
\hline Eldiario.es & 7 & 6 & 1 & 1 & EFE \\
\hline Levante & 7 & 4 & 3 & 1 & Europa Press \\
\hline El faro de Vigo & 6 & 5 & 1 & 0 & \\
\hline El Periódico & 6 & 5 & 1 & 1 & EFE \\
\hline El País & 5 & 3 & 2 & 1 & Europa Press \\
\hline
\end{tabular}

Fuente: elaboración propia.

Teniendo en cuenta los diarios analizados por Statista en su estudio Número de lectores diarios de los principales periódicos españoles en 2018 (en miles de lectores), merece la pena contabilizar el número de noticias sobre discapacidad publicadas por la prensa más leída, en su formato digital. Los diarios que coinciden entre los más leídos y los que más noticias sobre discapacidad han presentado han sido La Vanguardia (12 noticias), ABC (8), Levante (7), El faro de Vigo (6) y El País (5).

\section{Gráfico 5. Número de noticias sobre discapacidad en los diarios con mayor audiencia (ordenados de mayor a menor número de suscriptores)}

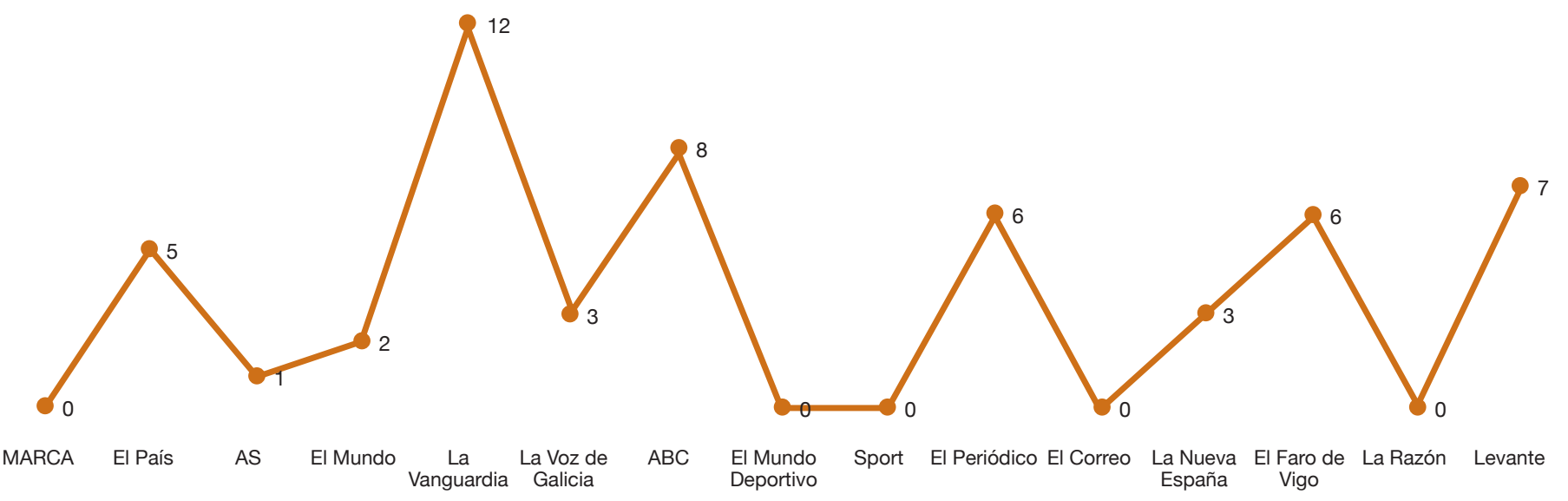

Fuente: elaboración propia con datos de Statista. 
En esta primera parte de la discusión de resultados se ha puesto el foco en el cumplimiento de la guía y en el origen de las informaciones. A continuación, se profundizará en el perfil de los protagonistas de estas noticias analizadas, es decir, las personas con discapacidad retratadas en la información.

La gran mayoría de las noticias sobre discapacidad (78\%) se refieren a colectivos de personas con discapacidad -en general o discapacidades concretas - y a sus actos, movimientos o reivindicaciones. Solo el $22 \%$ de las noticias sobre discapacidad tienen a individuos como protagonistas.

\section{Gráfico 6. Número de protagonistas de las informaciones analizadas}

Individuo

Colectivo

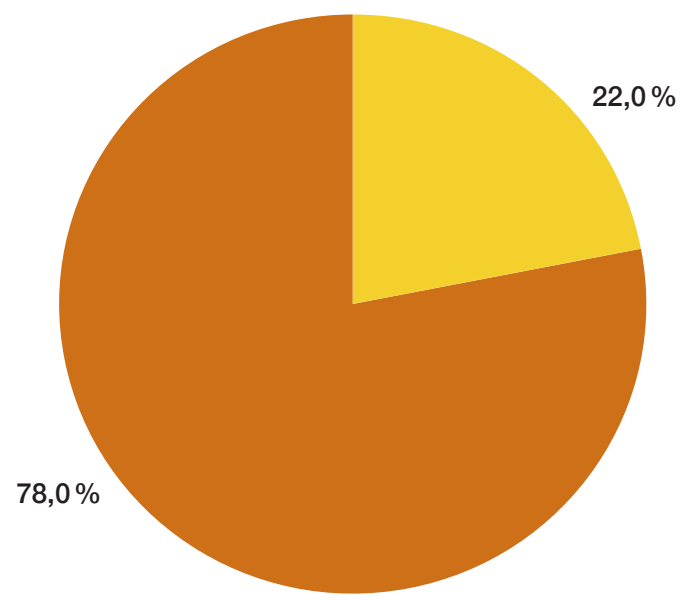

Fuente: elaboración propia.

Los datos han respaldado a Mariano Cebrián en su apunte de que "cuando estas personas aparecen en los medios audiovisuales, generalmente lo hacen desempeñando un papel representativo de su discapacidad" (2010: 5). Pocas noticias tienen a protagonistas individuales, y en estos casos, aparecen para convertirse en 'embajadores' de su discapacidad o para protagonizar noticias - generalmente negativas - relacionadas con sucesos. Dentro de las informaciones analizadas, dos noticias que se repiten en varios medios son las relacionadas con las elecciones del 28 de abril de 2019 en las que, por primera vez, pudieron votar aproximadamente 100.000 españoles con discapacidad intelectual; y noticias relacionadas con la celebración del 3 de mayo, primer Día Nacional de la Convención sobre los Derechos de las Personas con Discapacidad. En ambos casos, los reportajes elaborados al respecto presentaban el día a día de individuos con discapacidad para ilustrar -y generalizar - la rutina de las personas con el mismo tipo de discapacidad.

Por otro lado, la mayoría de las discapacidades representadas en las informaciones han sido de tipo intelectual (43 noticias), seguidas de las discapacidades físicas (33), las sensoriales (13), psicosociales (7) y enfermedad mental (4). Las discapacidades más nombradas han sido la movilidad reducida (12 informaciones), el síndrome de Down (7), trastorno del espectro autista y síndrome de Asperger (3), lesión medular (3) y parálisis cerebral (2). Esto significa que el tipo de discapacidad más abordada por las noticias analizadas ha sido la discapacidad intelectual. 
Sin embargo, retomando información del párrafo anterior, en el lapso de tiempo del que se ocupa el estudio tuvieron lugar las primeras elecciones en las que pudieron votar los españoles con discapacidad intelectual. Este hecho puede haber alterado los datos ofrecidos y haberles restado representatividad. José Manuel González (Servimedia) y José María Prieto (ONCE) opinan que este flujo de información es una fluctuación anómala y comparten la hipótesis de que la discapacidad física y la sensorial están más normalizadas en la prensa digital.

La enfermedad mental discapacitante ha resultado la menos representada en la muestra analizada. Este resultado coincide con las declaraciones aportadas por Belén Ruiz (CESyA), que comentaba en la fase de entrevistas que "la enfermedad mental está completamente discriminada (...) porque son discriminadas incluso por otras personas con discapacidad". Esto puede ser debido a que ha empezado a ser analizada muy recientemente, y supone un gran esfuerzo "entenderla más allá de su sintomatología dada la permanencia de creencias y conceptos equivocados que entorpecen la diferenciación entre enfermedad y discapacidad" (Cruz et al., 2011: 179).

\section{Gráfico 7. Tipos de discapacidades más nombradas en las informaciones analizadas}

$\begin{array}{r}50 \\ \hline 45 \\ \hline 40 \\ \hline 35 \\ \hline 30 \\ \hline 25 \\ \hline 20 \\ \hline 15 \\ \hline 10 \\ \hline 5 \\ \hline 0 \\ \hline\end{array}$

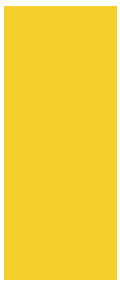

Fisica

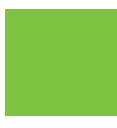

Sensorial

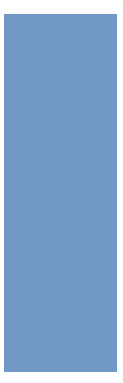

Intelectual

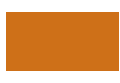

Psicosocial
Enfermedad mental

Fuente: elaboración propia.

Gráfico 8. Discapacidades concretas más nombradas en las informaciones sobre discapacidad analizadas

Movilidad reducida

Síndrome de Down

TEA y Asperger

Lesión medular

Parálisis cerebral

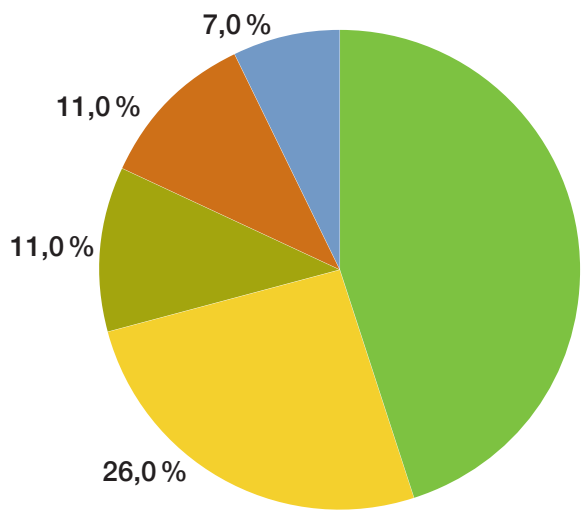

$45,0 \%$

Fuente: elaboración propia. 
En cuanto a las características de los protagonistas de las noticias analizadas, más allá del tipo de discapacidad, existe una brecha de género en la representación de las mujeres con respecto a los hombres. Aproximadamente 2 de cada 3 informaciones en las que se menciona el sexo de las personas participantes, tienen a hombres como protagonistas, lo cual contrasta con las opiniones de Ruiz Mezcua, que opinaba que no existía una brecha en este sentido. Asimismo, dentro del tercio restante protagonizado por mujeres hay noticias relacionadas con actos de protagonismo colectivo que reivindican la presencia de la mujer con discapacidad.

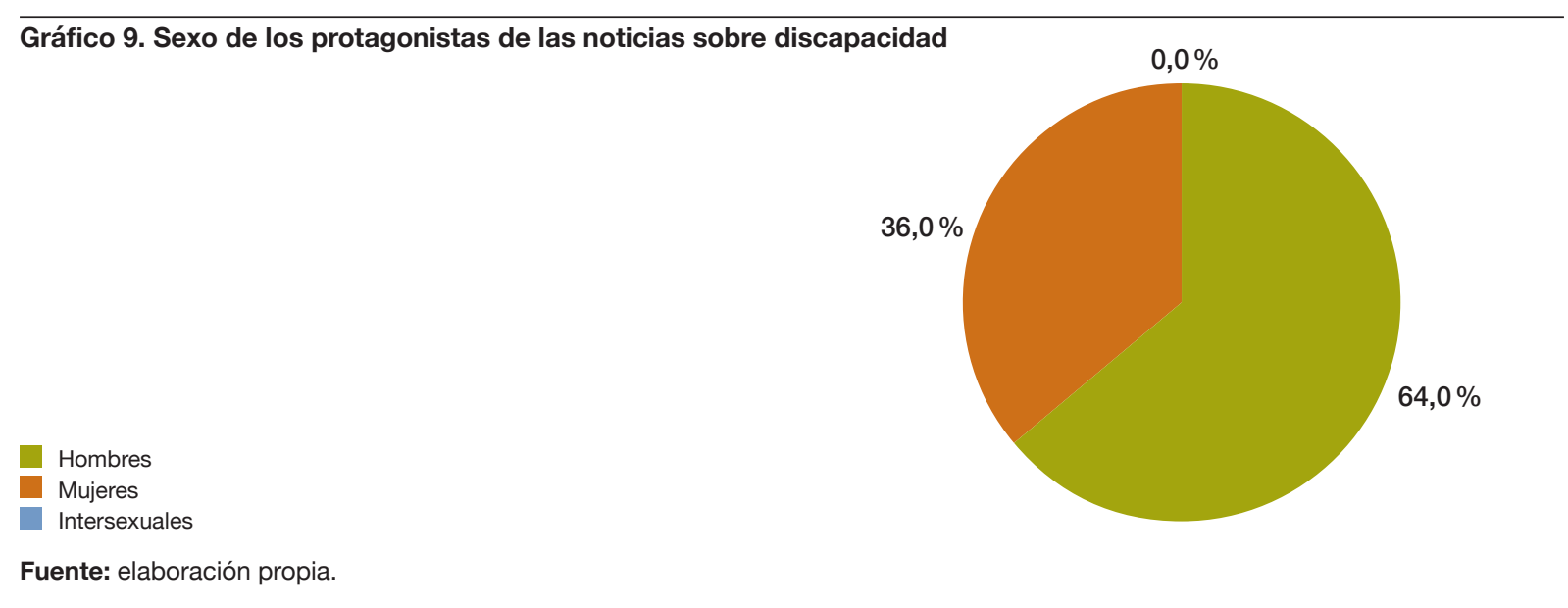

También se ha refutado la hipótesis de que los periódicos nacionales son los que publican más noticias sobre discapacidad. La prensa digital local y los suplementos locales de la 'gran prensa' - la que presenta un mayor índice de lectores - son los más concienciados con la elaboración de noticias de índole social, entre las que se encuentran aquellas sobre discapacidad, aunando el $58 \%$ de las informaciones analizadas. En segundo lugar, encontramos a la prensa nacional digital generalista (34\%) y, en tercer lugar, a la prensa especializada (8\%).

\section{Gráfico 10. Procedencia de las informaciones analizadas. Tipo de medio de prensa digital}

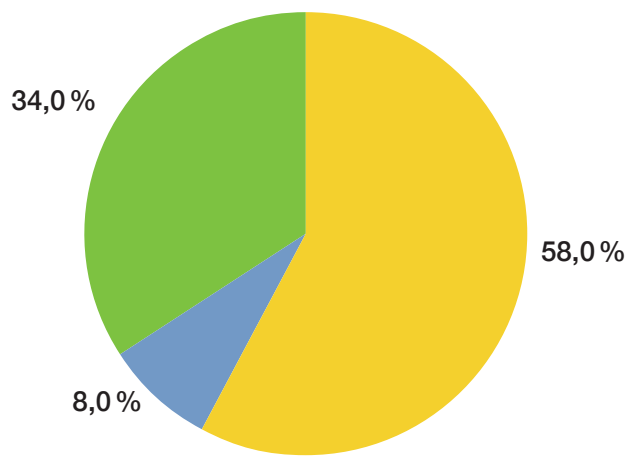

Fuente: elaboración propia. 
Por otro lado - obviando las secciones locales, que se incluyen en el punto anterior-, se confirma la hipótesis de que la sección generalista que más noticias sobre discapacidad aglutina es la de sociedad. Ana Rodrigo (EFE), José María Prieto (ONCE) y José Manuel González (Servimedia) coinciden en que existe una tradición de aglutinar las informaciones de tipo social y las referentes a colectivos en esta sección, aunque señalan que esta regla tiene sus excepciones.

\section{Gráfico 11. Secciones en las que aparece representada la discapacidad}

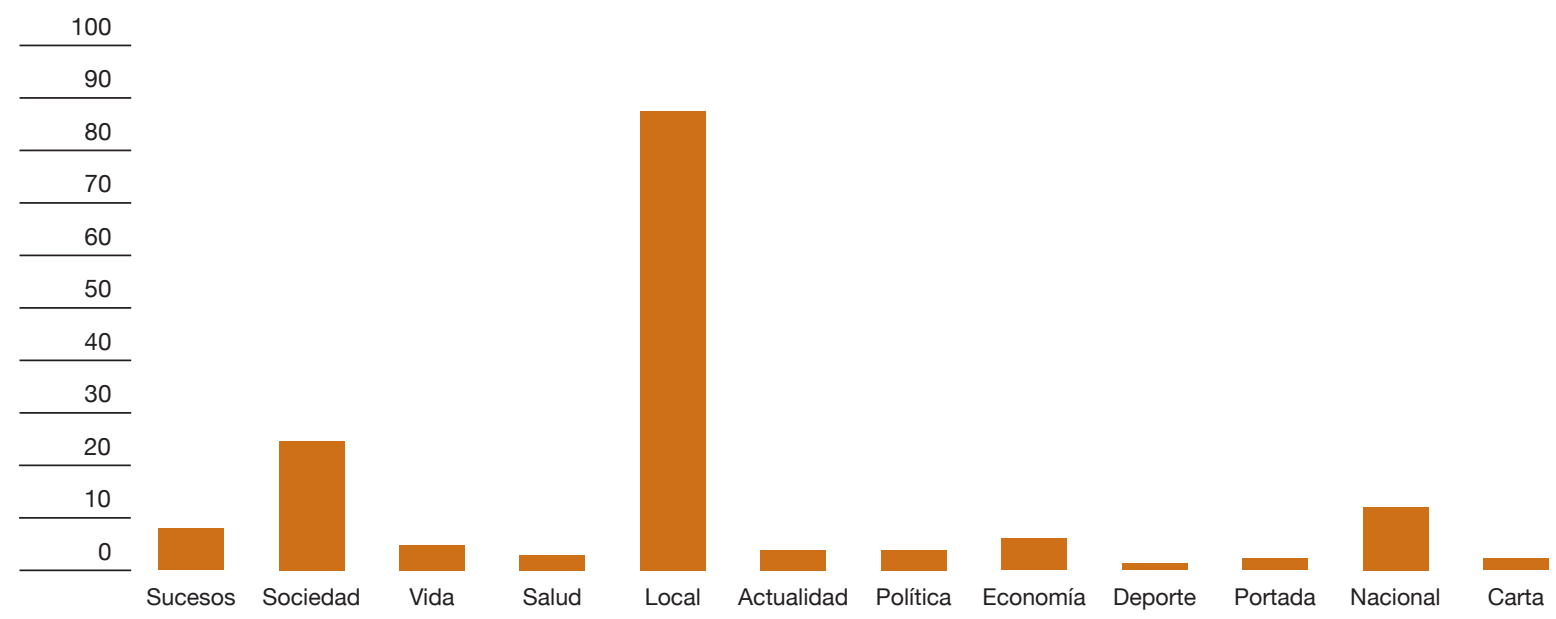

Fuente: elaboración propia.

\section{Gráfico 12. Género periodístico de las informaciones analizadas}

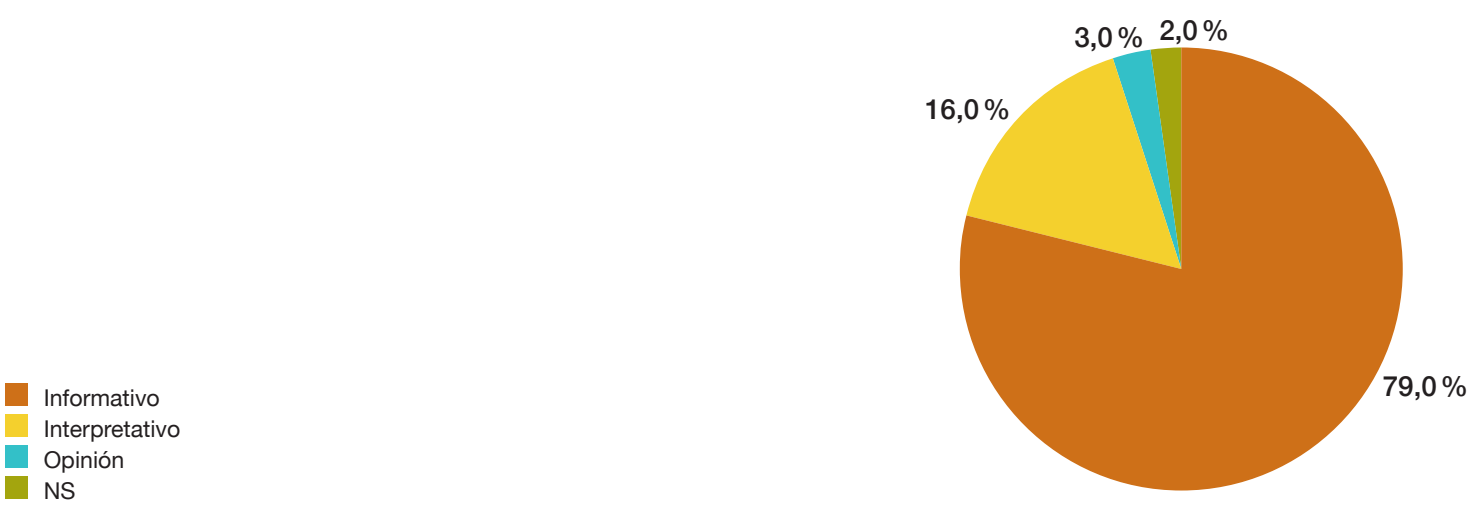

Fuente: elaboración propia.

También se ha comprobado que el género periodístico predominante en el trato de la información sobre discapacidad es la noticia. El $79 \%$ de la información proveniente de los medios de prensa digital analizados eran noticias, seguidas de un $16 \%$ de géneros interpretativos (reportaje interpretativo, crónica y entrevistas) y un $3 \%$ de opinión (cartas de los lectores y artículos de opinión). Este dato concuerda con el presentado 
por el Informe Anual de la Profesión Periodística 2018 de la Asociación de la Prensa de Madrid, que expone que los contenidos más demandados para los periodistas son las noticias y lo reportajes, seguidos de entrevistas y dejando, en último lugar, artículos de opinión (Hernández y Palacio, 2018: 17). Este dato muestra que, en el aspecto de la correspondencia de los géneros periodísticos, las noticias sobre discapacidad concuerdan con aquellas que no mencionan la discapacidad.

\section{Conclusiones}

La mayoría de las noticias analizadas cumplen con los códigos deontológicos y con la Guía de estilo sobre discapacidad para profesionales de los medios de comunicación (Hernández y Peñas, 2019). Se ha refutado la hipótesis de partida de que las noticias publicadas en prensa que incluyen a personas con discapacidad no cumplen las normas. Se ha comprobado que la mayoría de las informaciones digitales analizadas (el $70 \%$ ) cumplen con las indicaciones de la Guía de estilo. Además, todos los entrevistados coinciden en que la situación de la discapacidad en los medios de comunicación está mejorando paulatinamente, aunque todavía no se puede hablar de una completa normalización. El artículo 20 de la Constitución, que regula "el derecho a comunicar o recibir libremente información veraz por cualquier medio de difusión", puede entrar en conflicto con las normas de la guía de estilo en la medida en que el informador mencione o no la discapacidad de los sujetos protagonistas de la noticia. Los expertos consultados apuntan que la guía debería tener una función consultiva, pero no normativa. La responsabilidad de la redacción recae en los profesionales de los medios, que habrán de encontrar un equilibrio entre informar con el mayor número posible de datos, pero manteniendo el respeto hacia el colectivo de personas con discapacidad, evitando propiciar que se les relacione con una imagen negativa. Por ejemplo, en el caso de que un sujeto con discapacidad haya sido el autor de un delito, habrá que aclarar que no se puede asociar la conducta delictiva como una característica generalizada de las personas con discapacidad. Además, las noticias sobre discapacidad procedentes de agencias de noticias (especialmente Servimedia) suelen ajustarse a las normas de la Guía de estilo.

Se muestra una tendencia favorable en cuanto al tratamiento de la discapacidad en la prensa digital, con un mayor número de informaciones que representan esta condición de forma más normalizada.

El tipo de discapacidad que más ha aparecido en prensa en el periodo de tiempo estudiado ha sido la intelectual, coincidiendo con un contexto social puntual (primeras elecciones en las que este colectivo vota) que no tiene por qué corresponderse con una tendencia general. Este hecho puede haber alterado los datos ofrecidos y haberles restado representatividad. Por otro lado, la enfermedad mental discapacitante es la menos representada, siendo mencionada solo en cuatro de las doscientas informaciones.

La cobertura mediática de la discapacidad suele tener a protagonistas colectivos, y la protagonizada por individuos presenta una brecha de género en la que dos de cada tres noticias tienen como protagonistas a hombres, sin representación LGTBI. Pocas informaciones tienen a protagonistas individuales, y en estos casos, aparecen para convertirse en representantes de su discapacidad o para protagonizar noticias relacionadas con sucesos. 
Las informaciones sobre discapacidad suelen formar parte de la prensa digital local, pertenecen mayoritariamente al género de la noticia y se engloban en la sección de sociedad, seguida de la de sucesos (esta última sección es más común para noticias con protagonistas individuales). Se ha refutado la hipótesis de que los periódicos nacionales son los que publican más noticias sobre discapacidad. La prensa digital local y los suplementos locales de prensa nacional son los más concienciados con la elaboración de noticias sobre discapacidad. Por último, se confirma la hipótesis de que la sección que más noticias sobre discapacidad aglutina es la de sociedad. 


\section{Referencias bibliográficas}

Aguaded, V. (2014). "Heteronormatividad y medios de comunicación: estudio de la representación del colectivo de lesbianas, gays, personas transexuales y bisexuales en La que se avecina". En J. C. Suarez et al. (coords.), Libro de Actas del II Congreso Internacional de Comunicación y Género (pp. 12-23). Sevilla, Madrid: Universidad de Sevilla, Dykinson. Recuperado de https://idus.us.es/xmlui/handle/11441/36554.

AIPET, Asociación Iberoamericana de Periodistas Especializados y Técnicos (1994). "Normas de Ética y Deontología Profesional”. En J. C. Pérez-Fuentes (2004), Ética periodística. Principios, códigos deontológicos y normas complementarias (pp. 34-38). [s. I.]: Servicio Editorial de la Universidad del País Vasco.

Balas, M. (2006). "El tratamiento de la discapacidad en los medios de comunicación”. En L. Álvarez et al. (coords.), Comunicación y Discapacidades (pp. 315-320). Pontevedra: Colexio Profesional de Xornalistas de Galicia, Observatorio Galego dos Medios.

Bariffi, F. et al. (2008). La accesibilidad universal en los medios audiovisuales de comunicación. Ministerio de Educación, Política Social y Deporte; CESyA.

Burch, S. (25 febrero, 2003). Contribution on Common Vision and Key Principles for the Declaration. Comunicación presentada en II Prepcom de la CMSI "Cumbre Mundial sobre la Sociedad de la Información: visiones enfrentadas". Ginebra.

Califano, B. (2015). "Los medios de comunicación, las noticias y su influencia sobre el sistema político". Revista Mexicana de Opinión Pública, 19, pp. 61-79. DOI: https://doi.org/10.1016/j.rmop.2015.02.001.

Cebrián, M. (2010). Percepción de la imagen de las personas con discapacidad por los profesionales de los medios de comunicación. Madrid: Fundación ONCE.

Cortés-Fuentes, J. A. y Correyero-Ruiz, B. (2017). "Radio y empoderamiento social. Usos y gratificaciones del taller de radio para las personas con discapacidad intelectual o del desarrollo". El profesional de la información, 1(26), pp. 55-65. DOI: https://doi.org/10.3145/epi.2017.ene.06.

Cruz, M. et al. (2011). "La enfermedad mental severa desde la perspectiva del modelo social de la discapacidad". Index de Enfermería, 3(20), pp. 179-183. DOI: https://doi.org/10.4321/S1132-12962011000200009.

Díaz, L. (2007). "La representación de la discapacidad en los medios de comunicación. Cómo lograr una presencia más adecuada". Comunicación e Cidadanía, 1.

FELAP (1979). "Código latinoamericano de ética periodística”. En J. C. Pérez-Fuentes (2004), Ética periodística. Principios, códigos deontológicos y normas complementarias (pp. 30-33). [s. I.]: Servicio Editorial de la Universidad del País Vasco.

Fernández, A. (2004). "Las mujeres como sujeto histórico: género y enseñanza de la historia”. Didáctica de las ciencias experimentales y sociales, 18, pp. 5-24.

Fernández, M. et al. (2017). Tratamiento de la discapacidad en los medios de comunicación. Monográfico 9. Barcelona: Observatorio de la Discapacidad Física.

García, A. (2007). "Inmigración, ideología y medios de comunicación en Venezuela”. En F. Represa (coord.), Imaginarios del otro: realidad y percepción del fenómeno migratorio a través de los medios de comunicación (pp. 21-37). Burgos: Editorial Gran Vía. 
García, R. (2006). “La construcción de la realidad a través del lenguaje”. Eikasia: revista de filosofía, 3.

Garro, O. (2011). "Aprender a mirar: la mujer como sujeto activo de la representación". La ventana. Revista de estudios de género, 4(33), pp. 302-320.

Hall, S. (1997). Representation: Cultural Representations and Signifying Practices (Culture, Media and Identities). London: Sage.

Hernández, P. y Peñas, E. (2019). Guía de estilo sobre discapacidad para profesionales de los medios de comunicación. Madrid: Real Patronato sobre Discapacidad.

Hernández, R. y Palacio, L. (2018). Informe anual de la profesión periodística 2018. Madrid: Asociación de la Prensa de Madrid.

Huete, A. y Jiménez, A. (2018). Informe Olivenza 2017 sobre la situación general de la discapacidad en España. Madrid: Observatorio Estatal de la Discapacidad. Recuperado de https://observatoriodeladiscapacidad.info/ attachments/article/110/Informe \%20Olivenza \%202017\%20v5.7.pdf.

La Vanguardia (1986). “Libro de redacción”. En J. C. Pérez-Fuentes (2004), Ética periodística. Principios, códigos deontológicos y normas complementarias (pp. 238-241). [s. I.]: Servicio Editorial de la Universidad del País Vasco (pp. 238-241).

Luhmann, N. (2000). La realidad de los medios de masas. México: Anthropos, Universidad Iberoamericana.

Magallón, R. (2018). "La biblioteca digital sobre Donald Trump. Fact-checking frente a fake news". Estudios sobre el Mensaje Periodístico, 1(24), pp. 273-282. DOI: http://dx.doi.org/10.5209/ESMP.59949.

Marín, A. L. et al. (2003). Sociología de la comunicación. $2^{a}$ ed. Madrid: Trotta.

Martínez Hernando, B. (1998). "Alicia en el país de los géneros. Géneros periodísticos y géneros literarios”. Revista Comunicación y Estudios Universitarios, 8.

Moreau, M. C. (2005). "La prensa digital española: la configuración de un nuevo medio". En J. M. Desvois (coord.), Prensa, impresos, lectura en el mundo hispánico contemporáneo: homenaje a Jean-François Botrel (pp. 571584). París: Université Michel de Montaigne Bordeaux.

OATIC (2016). Accesibilidad de los Principales Medios Digitales de Comunicación. Observatorio Accesibilidad TIC. Discapnet. Recuperado de https://bit.ly/3ft6Bzk.

Orero, P. et al. (2009). "The Present and the Future of Audio Description and Subtitling for the Deaf and Hard of Hearing in Spain”. Meta Journal des traducteurs, 54(2), pp. 248-263. DOI: https://www.doi.org/10.7202/037679ar.

Pariser, E. (2011). The Filter Bubble: What the Internet is Hiding from You. London: Penguin UK.

Parratt, S. (2001). "El debate en torno a los géneros periodísticos en la prensa: nuevas propuestas de clasificación”. Zer: Revista de estudios de comunicación, 11(6).

Quesada, E. (1995). “Deontología profesional del periodista especializado y técnico”. En E. Bonete (coord.), Éticas de la información y deontologías del periodismo (pp. 276-279). Madrid: Tecnos.

Quirós, F. (2003). De críticos a vecinos del funcionalismo. Recuperado de: http://www.infoamerica.org/documentos_pdf/quiros01.pdf.

del Río, P. (1986). La imagen de las personas con deficiencias y el papel de los medios de comunicación. Madrid: FUNDESCO. 
Ríos, M. J. y Martínez, J. (1997). "La mujer en los medios de comunicación”. Comunicar: Revista Cientifica Iberoamericana de Comunicación y Educación, 9, pp. 97-104. Recuperado de: http://www.redalyc.org/articulo. oa? id=15800914.

Rodríguez, M. A. (2006). “¿Qué es la representación y cuál es su importancia para los estudios sociales?”. En M. Viveros et al. (comp.), De mujeres, hombres y otras ficciones: género y sexualidad en América Latina (pp. 3944). Bogotá: T/M Editores.

RTNDA (2000). Estados Unidos: Código de ética y de conducta profesional. Estados Unidos: Asociación de Directores de Informativos de Radio y Televisión. En J. C. Pérez-Fuentes (2004), Ética periodística. Principios, códigos deontológicos y normas complementarias (pp. 101-104). [s. I.]: Servicio Editorial de la Universidad del País Vasco.

RTVE (1981). "Principios básicos y líneas generales de la programación de los Medios dependientes del Ente Público RTVE”. En J. C. Pérez-Fuentes (2004), Ética periodística. Principios, códigos deontológicos y normas complementarias (pp. 248-257). [s. I.]: Servicio Editorial de la Universidad del País Vasco.

Terceiro, J. (1996). Sociedad digital: del homo sapiens al homo digitalis. Madrid: Alianza Editorial.

UNESCO (20 noviembre, 1983). Principios internacionales de ética profesional del periodismo. Comunicación presentada en la IV Reunión Consultiva de Periodistas, auspiciada por la UNESCO, Ciudad de México. Recuperado de https://dialnet.unirioja.es/descarga/articulo/5791502.pdf.

Utray, F. et al. (2010). "Actitudes y expectativas del colectivo de personas con discapacidad hacia la televisión". Pangea: revista de la Red Académica Iberoamericana de Comunicación, 1(1), pp. 54-73.

Washington Post (1999). "Standards and ethics". En J. C. Pérez-Fuentes (2004), Ética periodística. Principios, códigos deontológicos y normas complementarias (pp. 273-278). [s. I.]: Servicio Editorial de la Universidad del País Vasco. 